\title{
Caracterização cinemática de uma zona de cisalhamento transcorrente de direção NNE marcada na evolução de seu magmatismo granítico sintectônico na região de Camboriú, SC
} Kinematic characterization of a NNE-trending transcurrent shear zone, marked in the evolution of its syntectonic granitic magmatism in the region of Camboriu, SC

\author{
Amós Martini ${ }^{1}$ e Maria de Fátima Bitencourt ${ }^{1}$ \\ ${ }^{1}$ Programa de Pós-graduação em Geociências - PPGGEO, Instituto de Geociências, Universidade Federal do Rio Grande do \\ Sul - UFRGS, Avenida Bento Gonçalves, 9.500, Caixa Postal 15001, CEP 91501-970, Porto Alegre, RS, BR \\ (amosmartini@gmail.com; fatimab@ufrgs.br).
}

Recebido em 08 de agosto de 2013; aceito em 30 de junho de 2014

\begin{abstract}
Resumo
O Granito Corre-mar (GCM) localiza-se na região de Itapema-Camboriú, Santa Catarina, extremo nordeste do Cinturão Dom Feliciano. Uma zona de cisalhamento subvertical de direção NNE controla seu posicionamento, gerando um par S-C subvertical com cinemática sinistral. A foliação S (magmática), de direção NE-SW, é dada principalmente pela orientação de feldspatos e xenólitos, enquanto a foliação C (cisalhamento), de direção NNE-SSW, é marcada pelo estiramento dos cristais e formação de caudas de recristalização assimétricas nos feldspatos. Nas rochas encaixantes, próximo aos contatos, desenvolvem-se zonas de deformação de baixa temperatura paralelas à foliação C local do GCM. Os corpos do GCM têm uma sistemática variação na espessura, onde zonas mais largas mostram as foliações menos desenvolvidas. Microestruturas indicativas de deformação progressiva em temperatura decrescente são representadas por subgrãos em padrão tabuleiro de xadrez no quartzo e textura granoblástica em K-feldspato, as quais são superpostas por estruturas de mais baixa temperatura, como recristalização fina do quartzo, selamento de fraturas dos cristais maiores de feldspato por material da matriz finamente recristalizada e neoformação de grãos finos ao redor dos cristais de feldspato. A integração dos dados estruturais e petrológicos indica que o GCM se posicionou quando a zona de cisalhamento NNE estava ativa, e sua geometria indica uma componente de abertura na direção NE, típica de regime transtrativo. A estrutura transtrativa é compatível com sua posição em zona de baixa deformação transcorrente do Cinturão de Cisalhamento Sul-brasileiro, situada entre as zonas de mais alta deformação representadas pela zonas de cisalhamento Major Gercino e Itajaí, ativas no estágio pós-colisional do Ciclo Brasiliano no sul do Brasil.
\end{abstract}

Palavras-chave: Zona de cisalhamento transcorrente; Magmatismo granítico; Sintectônico.

\begin{abstract}
The Corre-mar Granite (GCM) is located in the region of Itapema-Camboriu, Santa Catarina, Brazil, in the northeastern part of Dom Feliciano Belt. A subvertical NNE-trending shear zone controls its emplacement, and a subvertical S-C fabric is generated with sinistral shear sense. The S-planes (magmatic) strike NE-SW and are marked mainly by the orientation of feldspar crystals and xenoliths, while the C-planes (shearing), strike NNE-SSW, marked by mineral stretching, tails of asymmetric recrystallization in feldspars, and inflection of the structures previously oriented along S. Low-temperature deformation zones parallel to the GCM local C-foliation, best developed near the contacts with the host rocks, do not extend more than a few meters into the country rocks. The GCM bodies have a systematic variation in thickness, where wider zones show the least developed foliations. Microstructures indicative of progressive deformation under decreasing temperature are represented by chessboardpattern subgrains in quartz, and granoblastic K-feldspar grains. These are overprinted by lower temperature microstructures, such as fine-grained recrystallized quartz, frequently by bulging, sealing of fractures in larger K-feldspar grains by the finely recrystallized matrix, and neoformation of fine grains around the feldspar crystals. The integration of structural and petrological data indicate that the GCM was positioned when the NNE-trending shear zone was active, and its geometry indicates an opening component along the NE direction, typical of transtensional regimes. The transtensional structure is compatible with its positioning in a low-strain zone of the Southern Brazilian Shear Belt, situated between the higher strain zones represented by the Major Gercino and Itajai shear zones, both active in the post-collisional stages of Brasiliano Cycle in southern Brazil.
\end{abstract}

Keywords: Transcurrent shear zone; Granitic magmatism; Syntectonic. 


\section{INTRODUÇÃO}

A evolução do magmatismo granítico no sul do Brasil está diretamente ligada ao Ciclo Brasiliano. As relações temporais entre o magmatismo e a atividade tectônica regional podem ser refletidas em diversas escalas, assim como na evolução das estruturas relacionadas ao resfriamento progressivo dos magmas (Florisbal et al., 2012a). A ascensão, o posicionamento e o tipo de deformação dos magmas graníticos podem variar muito de acordo com o ambiente tectônico do magmatismo.

Este trabalho propõe a investigação de uma zona de cisalhamento de direção NNE-SSW entre os municípios de Itapema e Balneário Camboriú, litoral norte de Santa Catarina, e sua possível relação com os granitoides ocorrentes na região, visando a contribuir com os trabalhos anteriores elaborados nessa área (Basei et al., 2000, 2008; Silva et al., 2005; Peternell et al., 2010), nos quais ficaram abertas questões estruturais e principalmente estratigráficas de algumas unidades ocorrentes na área. Os dados são aqui apresentados na forma de croquis de detalhe confeccionados a partir de croquis de campo e fotografias, estereogramas de foliações e lineações, fotografias e fotomosaicos de feições estruturais na escala meso e microscópica, com o objetivo de investigar a relação das estruturas do Granito Corre-mar (GCM) com as zonas de cisalhamento transcorrentes da região e, em maior escala, com os eventos transcorrentes do Cinturão Dom Feliciano (CDF).

\section{CONTEXTO GEOLÓGICO REGIONAL}

Uma grande massa de rochas graníticas compreende a parte leste do CDF, que se estende desde o Uruguai até Santa Catarina, subdividido em Batólito Pelotas, no Escudo Sulrio-grandense, Batólito Florianópolis, no Escudo Catarinense (EC) e Batólito Aiguá no Uruguai. Esse magmatismo foi controlado pelo Cinturão de Cisalhamento Sul-brasileiro (CCSb) (Figura 1A), definido por Bitencourt e Nardi (2000) como uma megaestrutura que compreende diversas zonas de cisalhamento anastomosadas, de espessura quilométrica e cinemática dominantemente transcorrente. A maior parte dessas zonas é subvertical, com direção variável entre NS e N60E, e deslocamento horário ou anti-horário. O CCSb, durante o estágio pós-colisional do Ciclo Brasiliano, controlou sucessivas etapas de magmatismo plutônico entre 650 e 580 Ma (Bitencourt e Nardi, 2000). A porção oeste do CDF mostra rochas metamórficas de fácies granulito arqueanas e paleoproterozoicas, relacionadas aos crátons Rio de La Plata (Almeida et al., 1973) e Luís Alves (Hartmann et al., 2003).

A Figura 1B dá ênfase ao EC, porção norte do CDF, que compreende, na parte sul, uma massa de granitoides pouco deformados; na parte norte, têm-se rochas do Complexo
Granulítico Santa Catarina (Hartmann et al., 1979), do Complexo Camboriú (CC) (Chemale et al., 1995) e pelo Granito Itapema (GI) (Bitencourt e Nardi, 2004); rochas supracrustais do Complexo Brusque, cuja idade de deposição ainda é discutida (Hartmann et al., 2003; Basei et al., 2008, 2011), além das zonas de cisalhamento regionais Major Gercino (ZCMG), definida por Bitencourt et al. (1989), e Itajaí-Perimbó (ZCIP), definida por Silva (1991). Ambas têm direção NE e cinemática destral, além de zonas conjugadas de menor escala com direção NS a NNE-SSW e cinemática sinistral. Diversos estudos na área (Bitencourt e Nardi, 1993, 2000; Florisbal, 2011; Peternell et al., 2010, entre outros) mostram que a tectônica controlou o posicionamento de magmas graníticos, gerando rochas fortemente foliadas e deformadas, sendo muitas vezes confundidas com rochas metamórficas. Florisbal et al. (2012b) obtiveram idades de cristalização entre 625 e $609 \mathrm{Ma}$ (U-Pb LA-ICP-MS em zircão) para granitoides sintectônicos às zonas de cisalhamento transcorrentes na área.

A área de estudo é uma região de aproximadamente $12 \mathrm{~km}^{2}$, focada principalmente em uma zona de cisalhamento de direção NNE-SSW, localizada entre a ZCMG e ZCIP (retângulo vermelho na Figura 1B). A área compreende rochas do CC e do GI intrudidas pelo GCM, Granito Serra dos Macacos (GSM) (UFRGS, 2000) e Granito Rio Pequeno (GRP) (Peternell et al., 2010).

Segundo UFRGS (2000), Lopes (2008) e Peternell et al. (2010), o CC compreende rochas bandadas a finamente laminadas, incluindo principalmente hornblenda-biotita ortognaisses de composição tonalítica a granodiorítica, com corpos decimétricos a métricos de anfibolito subordinados. Orto- e paragnaisses muitas vezes são migmatíticos, com leucossomas trondjemíticos a leucograníticos. A principal foliação do CC é formada pelo alinhamento de feldspatos, biotita (raramente anfibólio) e por lentes de agregados de quartzo e plagioclásio. Essa foliação é paralela ao bandamento e tem mergulhos variáveis tanto para NW quanto para SE (Peternell et al., 2010). Basei et al. (2013) apresenta novos dados sobre o CC, mostrando, através de datações $\mathrm{U} / \mathrm{Pb}$ e isótopos de $\mathrm{Hf}$, que este teve uma acresção juvenil, restrita ao Arqueano, seguida de diversos retabalhamentos intracrustais, que começaram no Paleomesoarqueano (3,3 a 3,0 Ga), continuaram por meio de eventos no Neoarqueano e Paleoproterozoico, terminando no Neoproterozoico (de 0,64 a 0,61 Ga).

O GI foi originalmente definido por Bitencourt e Nardi (2004) e compreende hornblenda-biotita granodioritos a biotita monzogranitos e leucogranitos equigranulares finos, sendo todos os termos ricos em xenólitos (Rivera et al., 2004). Um bandamento de fluxo $\left(\mathrm{S}_{0}\right)$ bem desenvolvido é encontrado em todas as suas variedades, conforme descrito por Bitencourt e Nardi (2004). Paralela à estratificação ígnea, desenvolve-se uma foliação magmática, e geralmente 


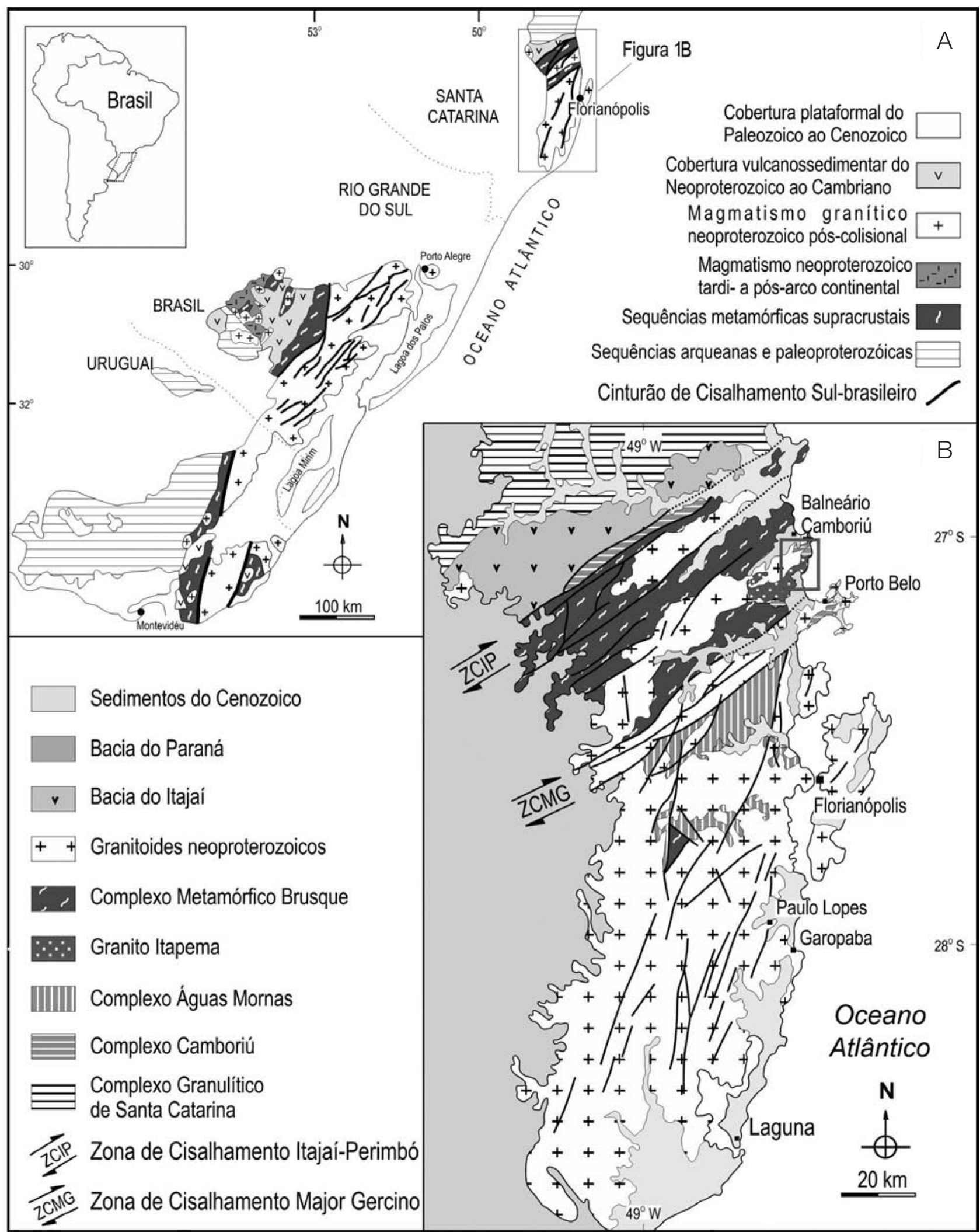

Figura 1. (A) Situação da área de estudo no contexto geológico e geotectônico do sul do Brasil e Uruguai e (B) no Escudo Catarinense com suas principais unidades geológicas e traços tectônicos; área de estudo indicada pelo retângulo. Modificado de Bitencourt e Nardi (2004). 
mergulha com baixo ângulo para SE e NW (Peternell et al., 2010). O GI foi datado em $2.02 \mathrm{Ga}$ (U-Pb SHRIMP em zircão) por Hartmann et al. (2003), sendo interpretada como idade de cristalização. No trabalho de Basei et al. (2013), a unidade referida como Diatexito Ponta do Cabeço parece tratar-se do próprio GI definido por Bitencourt e Nardi (2004). Aquele autor obteve a idade de $637 \pm 21 \mathrm{Ma}(\mathrm{U} / \mathrm{Pb}$ SHRIMP em zircão) para esta unidade, interpretando-a como idade da fusão neoproterozoica do CC que deu origem ao GI, segundo os dados apresentados por Basei et al. (2013).

O GRP, estudado por Florisbal et al. (2012c), compreende rochas porfiríticas de composição monzogranítica, raramente sienogranítica ou granodiorítica, com megacristais de feldspato imersos em uma matriz média a grossa contendo biotita como a principal fase máfica, e anfibólio nas fácies menos diferenciadas. Os mesmos autores obtiveram a idade de cristalização de $622 \pm 15 \mathrm{Ma}$ (U-Pb LA-ICP-MS em zircão).

O GSM compreende biotita sieno a monzogranitos com muscovita, fracamente foliados, de textura predominantemente equigranular fina a média, com fenocristais esparsos de feldspatos de $1 \mathrm{~cm}$ de tamanho. Sua idade de cristalização é $611 \pm 9 \mathrm{Ma}$ (U-Pb LA-ICP-MS em zircão) obtida por Florisbal et al. (2012c); O GSM e o GRP possuem características estruturais semelhantes, ambos com foliação magmática, praticamente sem deformação de estado sólido, de direção NE-SW e mergulhos de alto ângulo para NW e SE (Peternell et al., 2010).

Em mapas topográficos antigos, o local hoje conhecido como Ponta do Corre-mar, onde foi definida a seção tipo do GCM (UFRGS, 2000), consta como “Ponta do Cabeço". Isso gerou discussões a respeito da rocha ocorrente nesse local. Basei et al. (2013) defende que a única unidade ocorrente nesse local é a que esse autor chama de Diatexito Ponta do Cabeço, cortado por injeções graníticas tardias, que parecem corresponder ao GCM, sendo ambos colocados na mesma unidade. No presente trabalho serão apresentados dados de campo que possibilitam a individualização dessas unidades, GI e GCM, que indicam que esse se posicionou quando o GI já estava cristalizado, tornando incoerente a colocação de ambos dentro da mesma unidade estratigráfica. A idade do GCM ainda é tema de discussões, já que nas tentativas de datação feitas até hoje foram obtidas isócronas imprecisas. Basei et al. (2000) obteve, através do método U/Pb em zircão, um diagrama concórdia, pouco definido, com intercepto inferior em $583 \pm 26$ Ma, e intercepto superior em $2804 \pm 130$ Ma. Esse autor interpreta o intercepto inferior como idade de fusão parcial dos gnaisses encaixantes e cristalização do granito, e o superior como herança crustal. Silva et al. (2002) obteve uma datação U/Pb SHRIMP, porém também controversa, com um intercepto superior em $2174 \pm 22 \mathrm{Ma}$, e inferior em $868 \pm 330 \mathrm{Ma}$. Esse autor, comparando esses dados, interpreta a idade de $2174 \pm 22$ Ma como idade de cristalização, e a de $583 \pm 26$ Ma como crescimento hidrotermal do zircão. Entretanto, essas idades não são muito confiáveis, por não haver uma concórdia bem definida, dando margem a diferentes interpretações.

\section{GEOLOGIA DO GRANITO CORRE-MAR}

O GCM é um biotita monzogranito de textura heterogranular fina a média, localmente milonítico. Compreende corpos alongados de no máximo $2,5 \mathrm{~km}^{2}$, apófises de até 100 m de espessura e injeções centimétricas a métricas. Sua principal característica é a presença constante de duas foliações, uma magmática (S) e outra de cisalhamento (C), que formam uma estrutura tipo S-C, presente em todas as suas ocorrências. É comum a presença de xenólitos centimétricos a métricos de gnaisses e anfibolitos do CC, assim como xenólitos e megaxenólitos do GI. Diversas feições, desde macro a microescala, sugerem que o GCM foi submetido a tensões diferenciais durante e após sua cristalização.

\section{Estruturas de macroescala}

As intrusões do GCM são alongadas preferencialmente na direção NE-SW (045-065) (Figura 2), mas localizadamente podem infletir para NNE $\left(020^{\circ}\right)$, o que é observado principalmente em apófises e injeções menores. A foliação $S$ é paralela aos contatos e ao maior alongamento dos corpos.

\section{Estruturas de mesoescala}

A foliação S do GCM possui direção preferencial NE-SW com mergulhos acentuados ora para SE, ora para NW, enquanto a foliação C possui direção preferencial NNESSW com mergulhos subverticais ora para ESE, ora para WNW. No plano da foliação C, desenvolve-se uma lineação de estiramento marcada principalmente por cristais de plagioclásio e K-feldspato, com baixo ângulo de caimento. As atitudes dessas estruturas estão representadas na Figura 3, e no croqui mostrado na Figura 4.

A foliação S é marcada pela orientação de cristais de 0,5 a $1 \mathrm{~cm}$ de comprimento de plagioclásio e K-feldspato bem formados, orientação de agregados centimétricos de biotita e orientação de xenólitos centimétricos a métricos de gnaisses e anfibolitos do CC (Figuras 5A e 5B). Localmente, desenvolve-se uma estratificação composiconal paralela à S, dada pela segregação de pegmatitos e aplitos durante a cristalização, que tende a estar sempre paralela ou subparalela aos contatos do GCM.

A foliação C é marcada pelo estiramento e deslocamento dos xenólitos do CC anteriormente orientados na S, ora desenvolvendo schlieren, caudas de recristalização assimétricas (Figura 5C), que sugerem deformação não coaxial, nos 


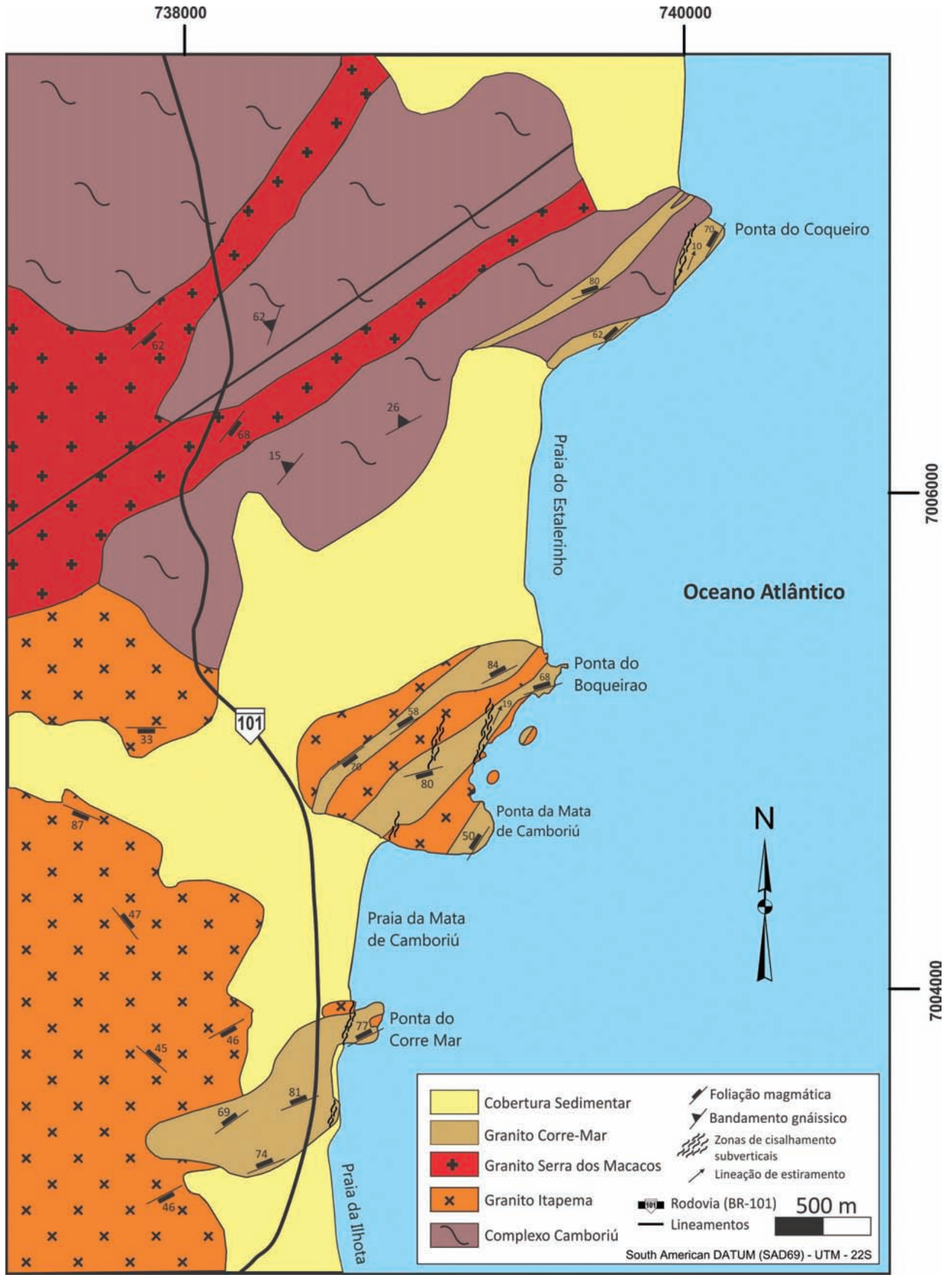

Figura 2. Mapa geológico da área de estudo. Modificado de Florisbal et al. (2011). 


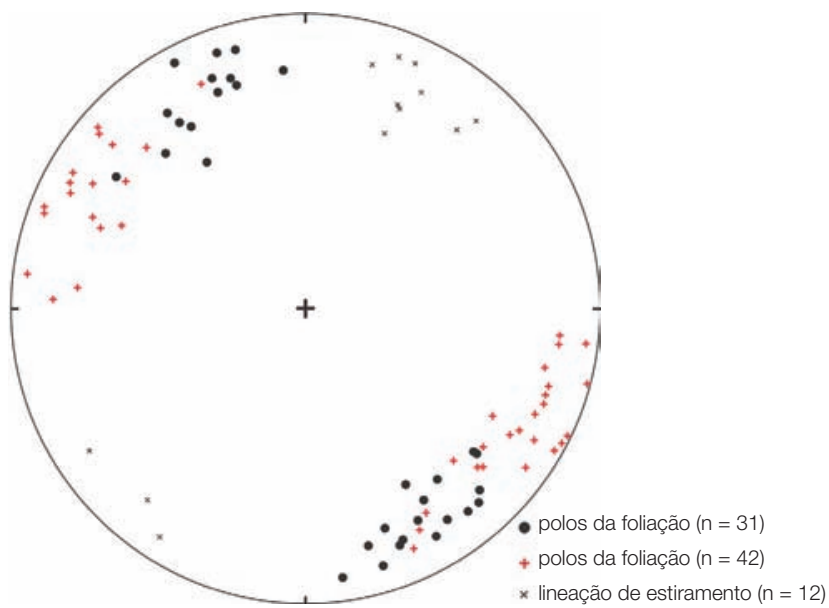

Figura 3. Representação estereográfica (hemisfério inferior) das estruturas do Granito Corre-mar.
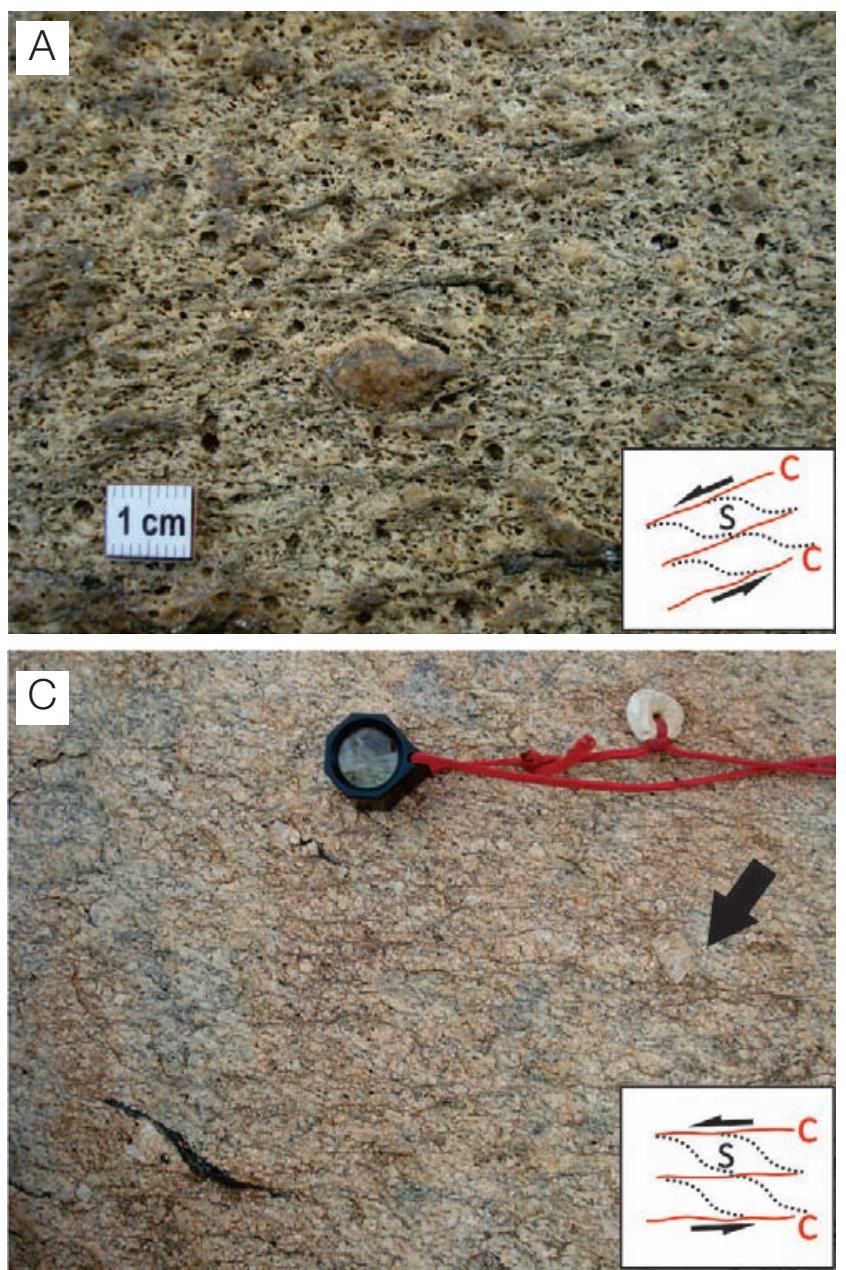

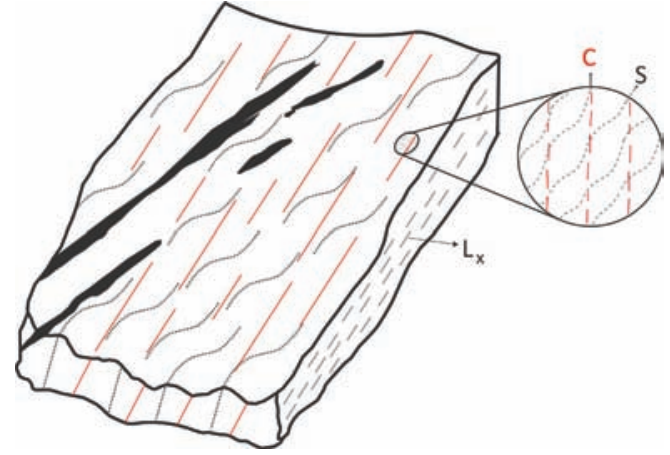

C: cisalhamento, S: magmática

Figura 4. Arranjo estrutural típico do Granito Corre-mar, com a foliação de cisalhamento penetrativa, e a foliação magmática subordinada e truncada, formando um par S-C, com o desenvolvimento de uma lineação de estiramento (Lx) no plano da foliação C.
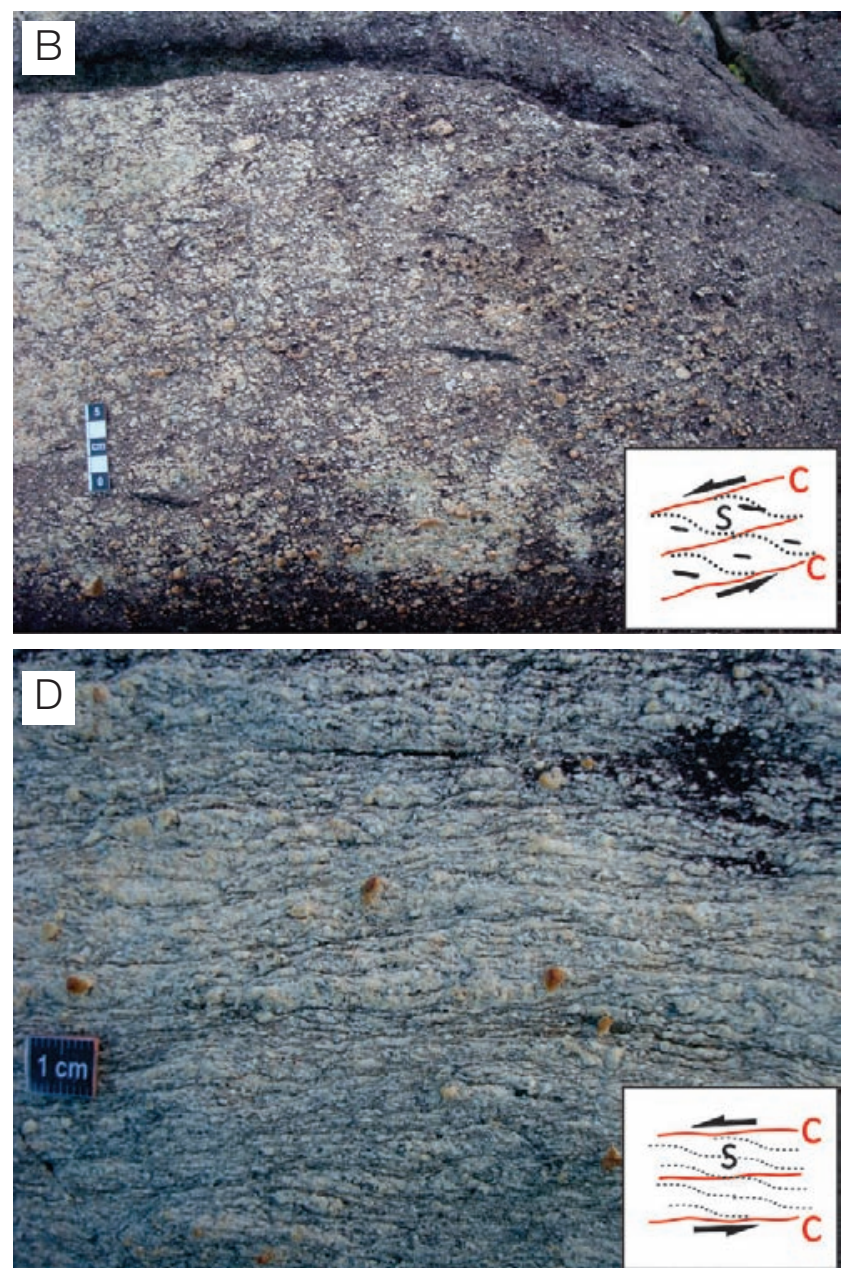

C: cisalhamento, S: magmática

Figura 5. Aspectos gerais das foliações do Granito Corre-mar, com a relação angular S-C. (A) Foliações S-C ressaltadas pela erosão diferencial, com um feldspato potássico (centro) orientado na $\mathrm{S}$ e deformado pelo cisalhamento ao longo da C, marcada por biotitas orientadas; (B) Xenólitos de gnaisse orientados na S; (C) xenólito de gnaisse orientado na S e deformado pelo cisalhamento ao longo da $\mathrm{C}$ (embaixo à esquerda) e um feldspato potássico com cauda assimétrica formada pela C (seta); (D) Textura porfiroclástica em zona de alta deformação, com o par S-C tendendo a se paralelizar. 
cristais de $\mathrm{K}$-feldspato e plagioclásio, e inflexão das biotitas da S para C que tornam o par S-C evidente.

Localizadamente, refletindo a heterogeneidade da deformação, ocorrem zonas de alto strain, que geram estiramento dos cristais de plagioclásio e K-feldspato e cominuição e recristalização intensa dos cristais de quartzo. Nessas zonas, observa-se a diminuição do ângulo entre a foliação magmática e a de cisalhamento. Alguns cristais de feldspatos resistem à deformação, gerando uma textura porfiroclástica, com matriz fina e porfiroclastos de até $0,5 \mathrm{~cm}$ (Figura 5D).

Próximo aos contatos das injeções do GCM com as rochas encaixantes ocorrem discretas zonas de deformação de baixa temperatura (ZDBT) marcadas pela intensa cominuição dos cristais de quartzo e feldspatos, concentradas em zonas estreitas, paralelas à foliação C local do GCM, mostrando uma continuidade das injeções para as encaixantes. As zonas de deformação de baixa temperatura têm sua ocorrência estritamente limitada às proximidades dos contatos com o GCM e não se estendem mais do que alguns metros para dentro das encaixantes (Figuras 6A e 6B).

Em alguns contatos do GCM com o GI se desenvolvem zonas de alta deformação que geram arrasto da foliação primária do GI encaixante para dentro das ZDBT (Figura 6C). Essas zonas têm até $3 \mathrm{~m}$ de largura e geram uma complexa obliteração dos limites dessas duas unidades, ficando difícil distingui-las. Próximo a esses contatos, observam-se xenólitos, injeções pegmatíticas e cristais das duas unidades com formato sigmoidal, por vezes dobrados, todos indicando sentido de movimento sinistral. As ZDBT são bem desenvolvidas perto desses contatos, se dissipando poucos metros para o interior do GI.

Injeções pegmatíticas e aplíticas encontram-se dobradas, com eixos subverticais e planos axiais paralelos à foliação C. Frequentemente ocorrem dobras cuja geometria indica movimento sinistral (Figuras 7A e 7B). O exemplo da Figura 7C mostra uma injeção preenchendo fraturas extensionais com direção WSW-ENE, que ajudam a reconstruir o campo tensional atuante no momento da ruptura do mush, indicando também uma cinemática sinistral. Localmente ocorrem séries de dobras fechadas (Figura 7D), com a C como plano axial.

O GCM mostra um padrão sistemático de bifurcação em várias escalas, contornando grandes xenólitos do GI e do CC. Em diversos afloramentos, além da componente sinistral é notável uma componente trativa, controlando o posicionamento do GCM, evidenciada por uma variação na espessura dos seus corpos e injeções, onde as zonas mais largas encontram-se pouco deformadas, com as foliações e lineações pouco desenvolvidas.

Nos locais onde o GCM é intrusivo nas rochas do CC ocorrem xenólitos de gnaisse e anfibolito, muitas vezes angulosos e com contatos retos, aparentemente sem interação com o magma do GCM. Porém, localmente, xenólitos alongados
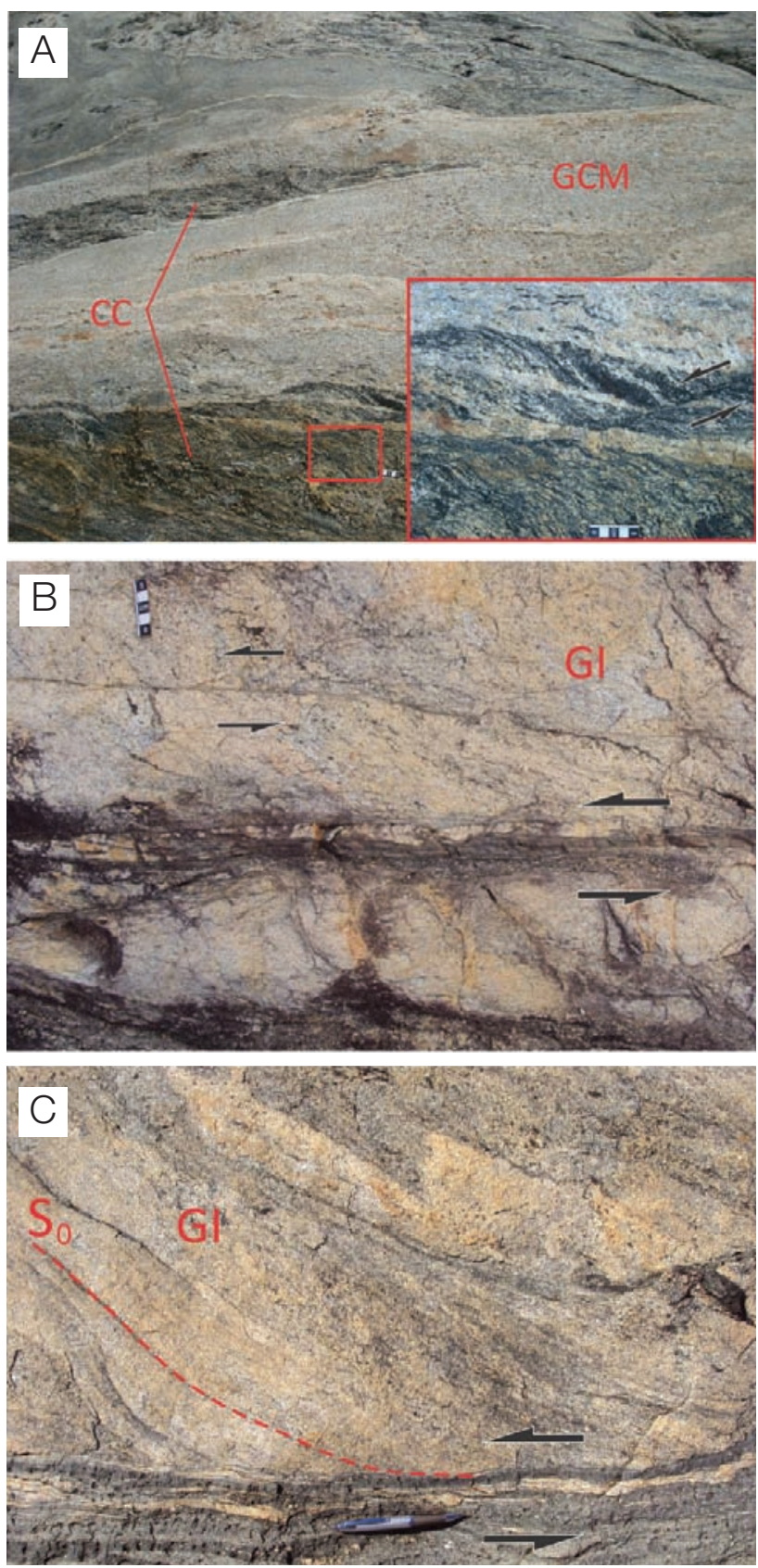

GCM: Granito Corre-mar, CC: cinturão de cisalhamento, Gl: Granito Itapema, S: magmática

Figura 6. Feições de deformação nas rochas encaixantes do Granito Corre-mar. (A) Injeção do Granito Corre-mar em gnaisse do CC (detalhe em vermelho: zoom da parte destacada mostrando o bandamento gnáissico deslocado por uma zona de deformação de baixa temperatura, concordante com a foliação de cisalhamento local do Granito Corre-mar); (B) zona de deformação de baixa temperatura afetando o Granito Itapema; (C) bandamento de fluxo $\left(S_{0}\right)$ do Granito Itapema arrastado para uma zona de deformação de baixa temperatura. 
são orientados e parcialmente assimilados (Figura 8A). Em alguns, o granito penetra no bandamento gnáissico, aproveitando a estrutura pré-existente, como no detalhe da Figura 8A. Alguns xenólitos centimétricos a decimétricos são deformados e estirados ao longo da foliação $\mathrm{C}$, gerando um formato assimétrico que indica movimento sinistral (Figura 8B). É frequente também a ocorrência desses xenólitos muito estirados concordantes com a foliação C, formando schlieren, que são muitas vezes confundidos com agregados de biotita do próprio GCM (Figura 8C).

O contato entre o GCM e o GI é melhor exemplificado na seção tipo do GCM, onde o croqui da Figura 9 mostra diversas relações geométricas e estratigráficas entre ele e sua encaixante. Nessa figura observa-se uma zona de contato intensamente cisalhada entre o GI e o GCM, paralela à foliação C do GCM. Essa zona mostra uma intercalação dos dois granitos, com diversos indicadores cinemáticos, como xenólitos com formato sigmoide, inflexão da foliação do GI e formato de injeções centimétricas do GCM, indicando um sentido de movimento sinistral. Essa zona de contato mostra também uma componente de abertura (parte norte da figura) onde os xenólitos aparecem menos deformados e a foliação pouco afetada (quadro na parte superior direita). A foliação do GI é arrastada e tende a se paralelizar com a zona. Na porção noroeste do croqui ocorrem as ZDBT, com a mesma orientação da zona de contato e da foliação $\mathrm{C}$ do GCM, que se restringem às proximidades dos contatos com as injeções do GCM. Na parte leste da figura, a foliação C do GCM mostra um comportamento penetrativo e homogêneo da rocha, e a foliação $\mathrm{S}$ se torna mais desenvolvida e menos espaçada em direção ao contato.
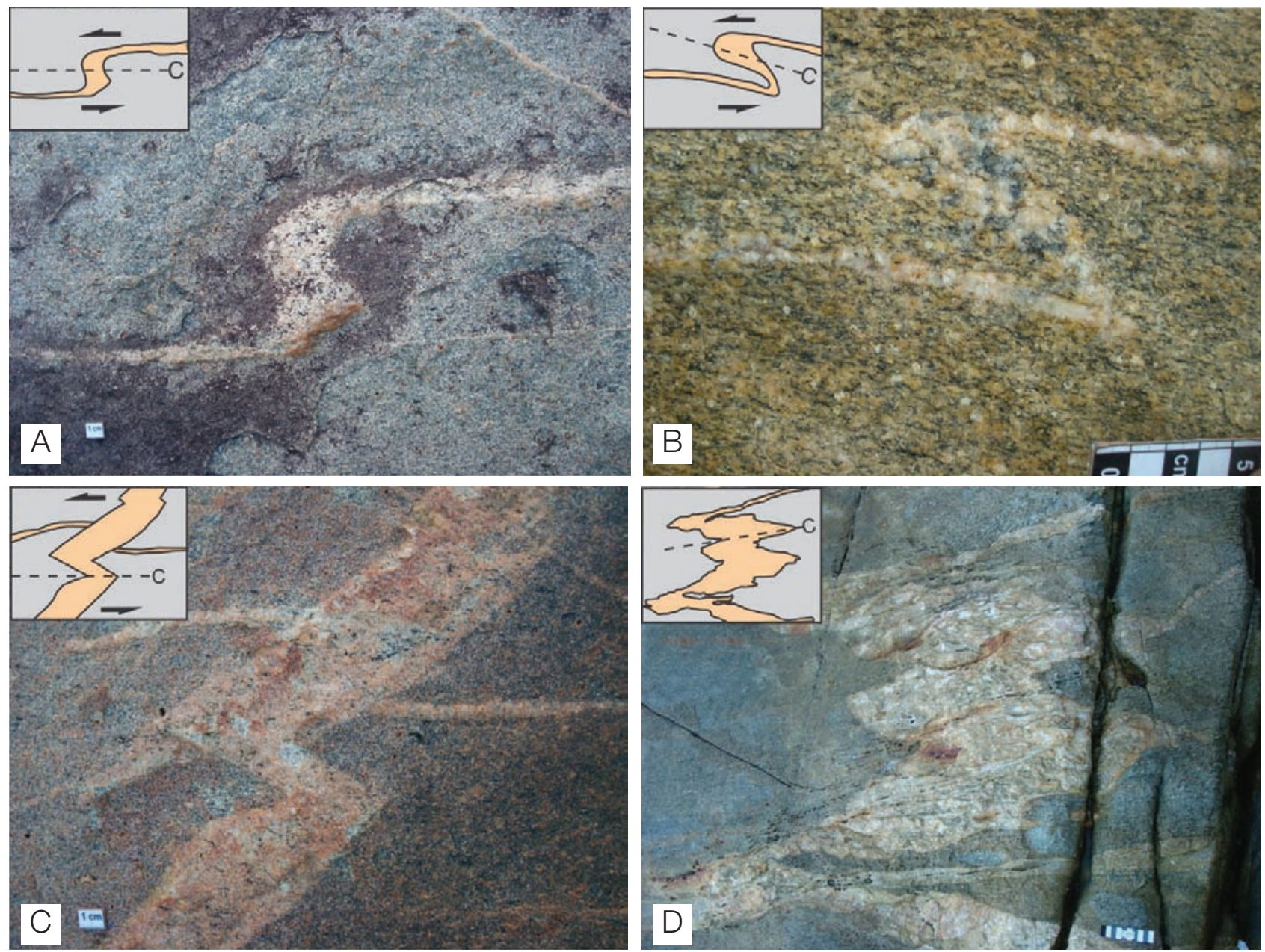

C: cisalhamento

Figura 7. Injeções aplíticas e pegmatíticas dobradas com respectivos croquis interpretativos. (A) injeção aplítica com dobra em S aberta; (B) injeção aplítica com dobra em S fechada; (C) injeção preenchendo fraturas extensionais; (D) séries de dobras fechadas a isoclinais em injeção aplítica. 

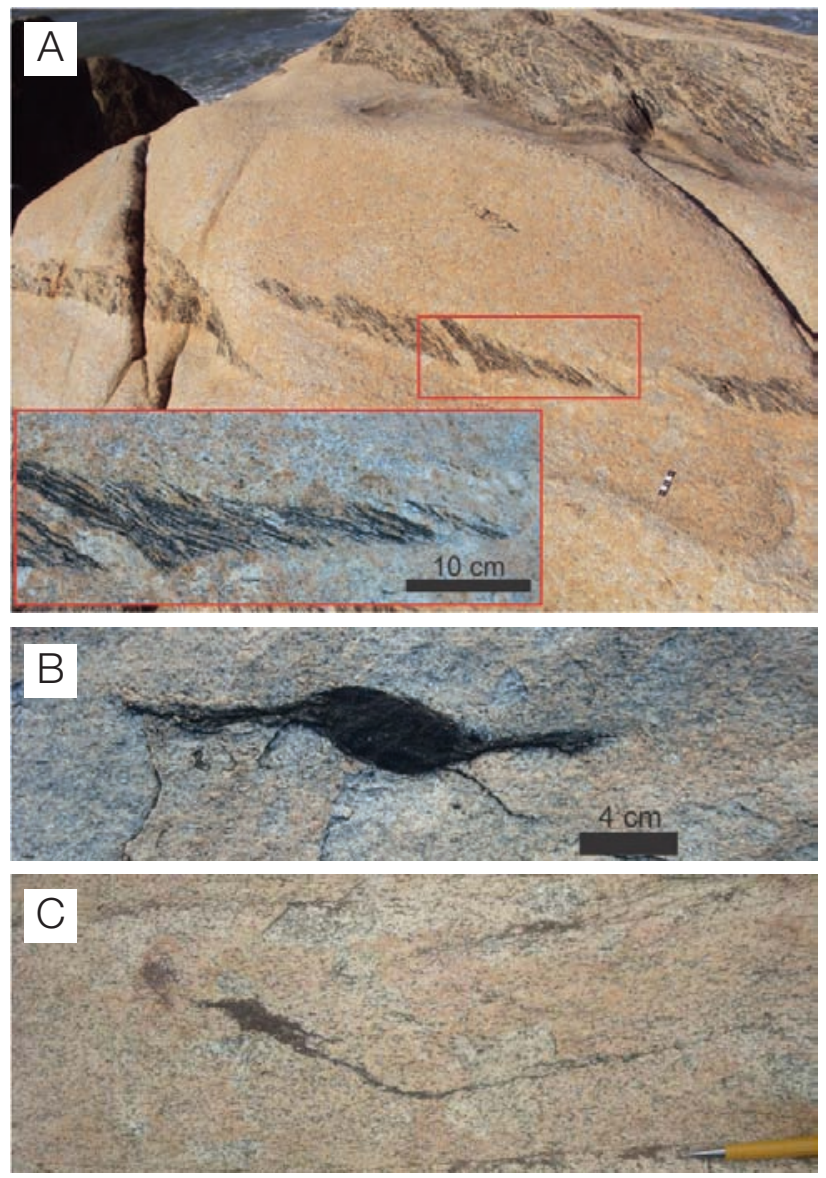

Figura 8. (A) Xenólito alongado de gnaisse do cinturão de cisalhamento em injeção do Granito Corre-mar; retângulo vermelho: detalhe da foto $(A)$ mostrando o xenólito parcialmente assimilado pelo magma granítico; (B) xenólito de anfibolito estirado pelo cisalhamento ao longo da foliação de cisalhamento assimetricamente, com movimento sinistral; (C) xenólito estirado e desagregado, formando schlieren.

\section{Petrografia e microestruturas}

O GCM compreende biotita monzogranitos de textura heterogranular a seriada fina a média, sendo biotita o principal mineral varietal, aparecendo muscovita em menor quantidade nos termos mais diferenciados. Os minerais acessórios são alanita, titanita e zircão. O índice de cor (M') é de cerca de 5 , mas pode alcançar 10 nos termos menos diferenciados. O par S-C é nítido em escala microscópica, dado especialmente pela orientação das micas. A S é marcada pela orientação de cristais de até $1 \mathrm{~cm}$ de feldspatos, e agregados de biotita e muscovita. Já a foliação C é marcada pela inflexão das micas da $\mathrm{S}$ para a $\mathrm{C}$, estiramento e quebra dos cristais de feldspato, acompanhado frequentemente de formação de subgrãos e recristalização localizada, principalmente por rotação de subgrão (RSG). O cisalhamento ao

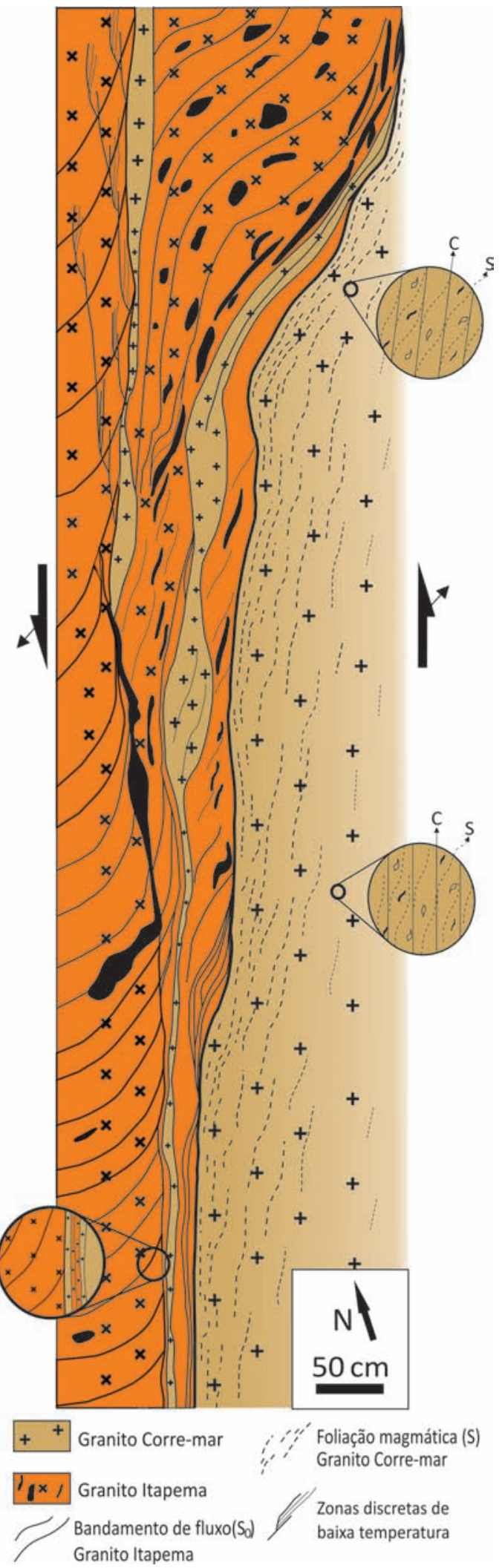

Figura 9. Relações de contato entre o Granito Corre-mar e sua encaixante (Granito Itapema) na Ponta do Corre-mar, seção-tipo do Granito Corre-mar. 
longo dos planos $\mathrm{C}$ gera recristalização nos feldspatos, formando caudas assimétricas que indicam cinemática sinistral.

Tanto o quartzo como os feldspatos têm extinção ondulante, que é sempre mais desenvolvida no quartzo. É notável a sobreposição de feições de mais baixa temperatura nas de temperatura mais alta, ao longo das mesmas estruturas planares, tais como grãos finamente recristalizados, comumente por bulging $\left(300-450^{\circ} \mathrm{C}\right)$ (Shigematsu, 1999; Stipp et al., 2002) nas bordas de grãos de feldspato de textura granoblástica média a grossa, e quartzo com subgrãos em padrão tabuleiro de xadrez. Essas microestruturas de mais alta temperatura são comumente fraturadas, com preenchimento pela matriz ígnea. Devido à heterogeneidade da deformação, zonas de mais alto strain geram considerável cominuição dos cristais de quartzo e feldspatos, dando origem a uma textura porfiroclástica e a estruturas do tipo manto/núcleo (Passchier e Trouw, 2005) (Figura 10).

O K-feldspato preserva ainda algumas faces retas. A extinção ondulante evolui muitas vezes para subgrãos nas bordas dos cristais, e eventualmente ocorre rotação dos subgrãos e formação de novos cristais. Localmente, os cristais têm textura granoblástica poligonal média a grossa que indica terem sido formados em temperaturas da ordem de $650^{\circ} \mathrm{C}$ (Yund e Tullis, 1991; Vidal et al., 1980) (Figura 11A). A presença de macla xadrez é comum, assim como pertitas em chama, e ambas são distribuídas heterogeneamente nos cristais (Figura 11B). Debat et al. (1978) e Passchier (1982) definem a pertita em chama como uma feição comum em rochas submetidas a altas tensões diferenciais na fácies xisto verde, especialmente em zonas de cisalhamento e tendem a se formar das bordas para o centro dos cristais, onde a tensão e a instabilidade do cristal tendem a ser maiores.

O plagioclásio $\left(\mathrm{An}_{10-19}\right)$ tem forma arredondada, com raras faces retas. É comumente zonado, e a zonação é acentuada pela alteração diferencial dos núcleos dos cristais. É comum a ocorrência de maclas encurvadas (Figura 11C) e kink-bands nas maclas polissintéticas. Apresentam frequentemente macla tectônica (Figura 11C) e, assim como o K-feldspato, os cristais de plagioclásio apresentam extinção ondulante, subgrãos e, localizadamente, recristalização por RSG (Figura 11C), que indica temperaturas acima

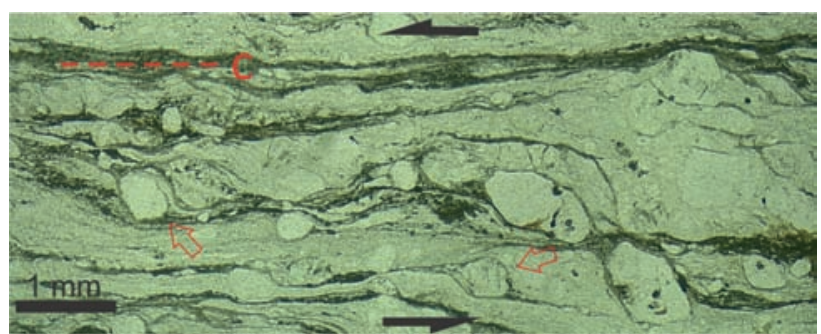

Figura 10. Zona de milonitos do Granito Corre-mar com estruturas do tipo manto-núcleo indicando deformação sinistral (setas vazias). (Nicois paralelos). de $600^{\circ} \mathrm{C}$ (Olsen e Kohlstedt, 1985; Yund e Tullis, 1991; Jensen e Starkey, 1985).

O quartzo ocorre principalmente como agregados intersticiais, e em menor quantidade como inclusões globulares de até $1 \mathrm{~mm}$ nos feldspatos. É bastante comum a ocorrência de grãos recristalizados por RSG e por migração de limite de grão (MLG) (Figura 11D). Frequentemente ocorrem antigos cristais maiores com as bordas intensamente recristalizados principalmente por RSG (Figura 11E). Em zonas de mais alta deformação ocorre quartzo fitado, principalmente entre cristais de feldspato. Localizadamente, relictos de quartzo com dois conjuntos ortogonais de subgrãos implicam a ativação de deslizamento prismático -c típico de temperaturas acima de $600^{\circ} \mathrm{C}$ (Mainprice et al., 1986). De acordo com Kruhl (1996), essa estrutura, denominada tabuleiro de xadrez, se forma em temperaturas superiores a $650^{\circ} \mathrm{C}$, em condições de pressão normal (Figura 11F).

A biotita ocorre tanto em agregados quanto cristais individuais, que marcam a foliação $\mathrm{S}$ e sofrem inflexão no sentido anti-horário para a foliação C, condizente com a deformação sinistral verificada no GCM. São comuns micas finas neoformadas nas bordas dos cristais de K-feldspato e plagioclásio. A biotita possui cor castanha a castanha esverdeada para ng e comumente apresenta microestruturas do tipo mica-fish com movimento sinistral.

Alanita euédrica é comum no GCM, tendo frequentemente bordas de epidoto. Zircão forma inclusões principalmente na biotita. Titanita bem formada ocorre como acessório subordinado.

\section{CONSIDERAÇÕES FINAIS E CONCLUSÕES}

As estruturas de macro- a microescala observadas no GCM apontam para uma evolução controlada por tectônica transcorrente associada ao CCSb, conforme interpretado por Peternell et al. (2010). A ocorrência de uma zona de cisalhamento subvertical de direção NNE-SSW, com cinemática de transtração sinistral, controlando a intrusão do GCM, permite interpretá-la como estrutura subordinada às zonas de transcorrência do CCSb na área, de direção NE-SW (Figura 12). A zona estudada funcionou como uma componente antitética do regime regional destral relacionado às zonas de cisalhamento regionais Major Gercino e Itajaí-Perimbó, resultando em uma componente de abertura. Casos semelhantes a esse, onde ocorrem zonas antitéticas com componentes de abertura, são descritos na província Borborema (Weinberg et al., 2004).

O par S-C do GCM esteve ativo durante seu posicionamento, porém a foliação $C$ persistiu após o estágio magmático e, com o resfriamento do magma, gerou estruturas cada vez mais rúpteis até a temperatura da intrusão equilibrar-se 

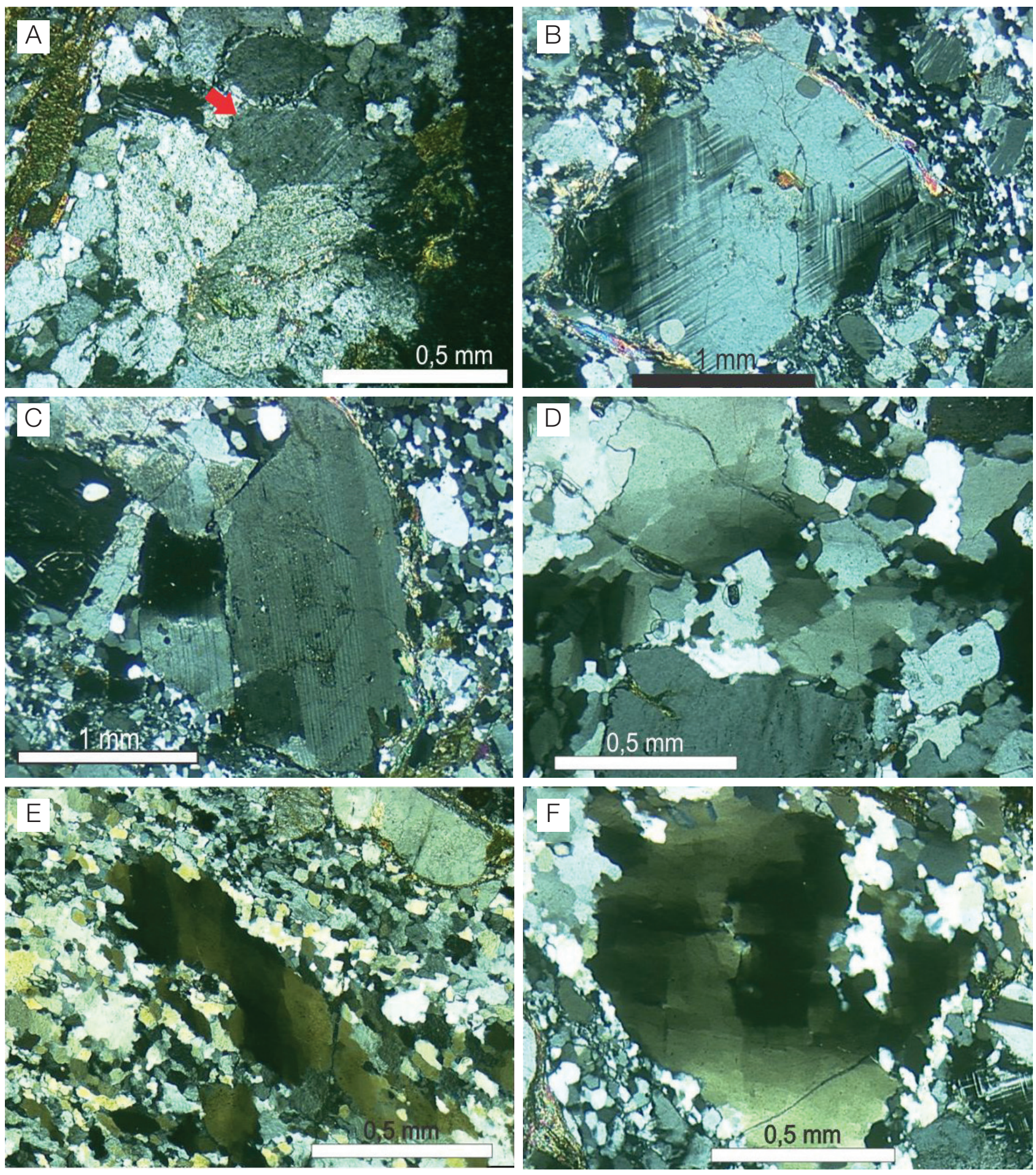

Figura 11. Feições petrográficas e microestruturais do Granito Corre-mar (Nicóis cruzados). (A) textura granoblástica com contatos a $120^{\circ}$ e contatos poligonais (seta) em cristais de K-feldspato; (B) cristal de K-feldspato mostrando a dupla macla distribuída heterogeneamente no cristal e pertita em chama (borda inferior esquerda do cristal); (C) cristal de plagioclásio com recristalização por rotação de subgrão (embaixo e à esquerda); (D) cristais de quartzo com extinção ondulante, subgrãos, recristalização por rotação de subgrão e, subordinadamente, migração de limite de grão; (E) cristal relicto de quartzo com as bordas recristalizadas principalmente por rotação de subgrão; (F) cristal relicto de quartzo mostrando padrão tabuleiro de xadrez, com as bordas recristalizadas por rotação de subgrão (acima à direita). 


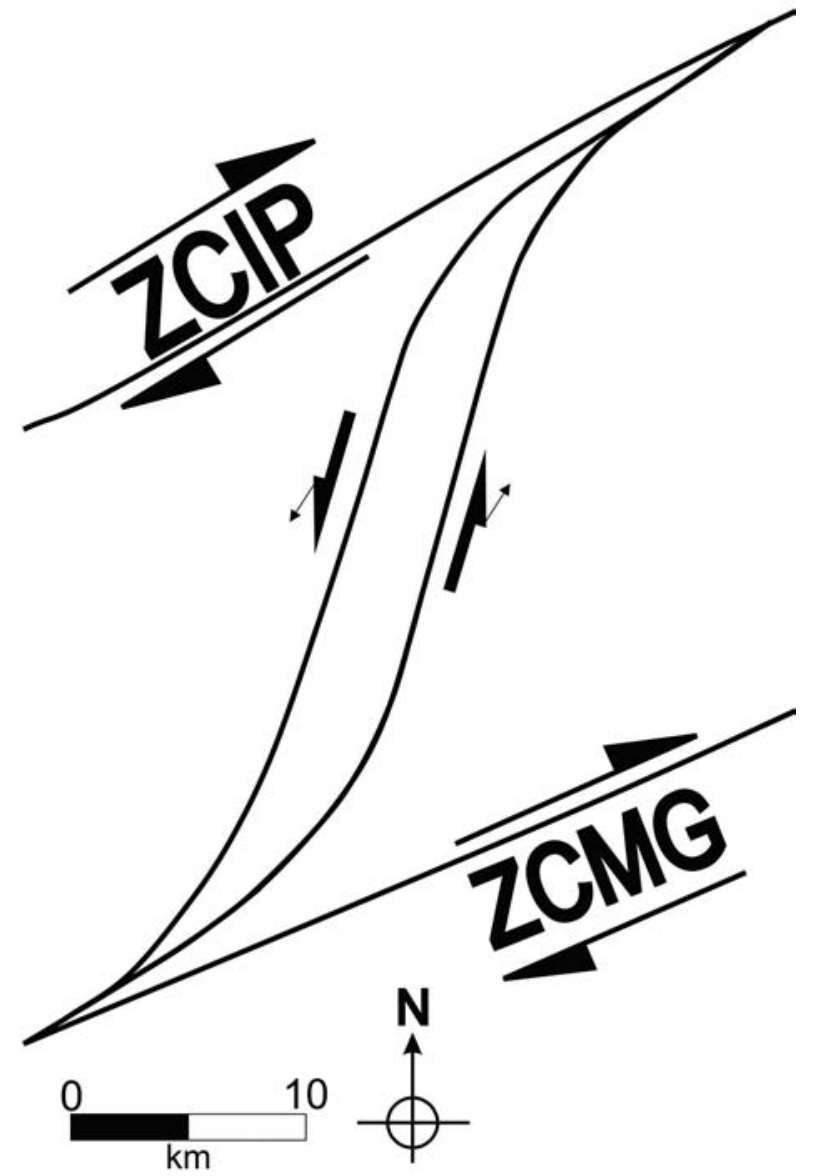

ZCIP: zona de cisalhamento Itajaí-Perimbó, ZCMG: zona de cisalhamento Major Gercino.

Figura 12. Representação hipotética do posicionamento da zona de cisalhamento que afeta o Granito Corre-mar, em relação às zonas de cisalhamento Major Gercino e Itajaí-Perimbó, indicando uma transtração sinistral.

com a da encaixante, o que indica que o posicionamento do GCM se deu em nível crustal não muito profundo.

As zonas de deformação de baixa temperatura encontradas no CC e no GI próximas aos contatos com o GCM representam o efeito da mesma deformação que afetou ductilmente o GCM, gerando a foliação C, porém com mais baixa temperatura pelo fato de as encaixantes já estarem frias. No momento da intrusão do GCM, a deformação se concentrou preferencialmente no magma, resultando em deformação limitada das encaixantes, em condição dúctil-rúptil.

Feições de deformação de alta temperatura, como subgrãos em padrão tabuleiro de xadrez no quartzo, e textura granoblástica poligonal grossa no K-feldspato, ainda que localmente, indicam que o sistema sofreu deformação em temperaturas da ordem de $650^{\circ} \mathrm{C}$, compatíveis com as da fácies anfibolito superior e com a temperatura solidus de composições graníticas. Pelo fato de esta deformação ser de alta temperatura e, dada a preservação de estruturas e texturas típicas de rochas ígneas, como cristais de plagioclásio zonados e cristais de quartzo reliquiares grandes e ausência de minerais metamórficos, conclui-se que essa deformação é de caráter magmático, e que a mesma se dá durante ou logo após a cristalização.

As feições de recristalização fina, bem desenvolvida e distribuída homogeneamente no GCM indicam evento de deformação de mais baixa temperatura ao longo das mesmas estruturas. Feições que atestam o caráter de baixa temperatura, como geração de micas finas neoformadas; recristalização fina do quartzo, comumente com bulging; selamento de fraturas dos cristais maiores de feldspato por material fino da matriz finamente recristalizada e neoformação de grãos finos ao redor dos cristais de K-feldspato de maior tamanho são indicativos de deformação em temperaturas da ordem de 300 a $450^{\circ} \mathrm{C}$, bem abaixo da temperatura solidus do sistema granítico, e compatíveis com as da fácies xisto verde. A sobreposição das feições formadas em temperatura mais alta por evento de temperatura mais baixa ao longo das mesmas estruturas planares sugere que essas são a evolução do evento de alta temperatura, representando dessa forma que a progressão do rebaixamento da temperatura da zona de cisalhamento é controlada pelo resfriamento do magma.

A integração entre geologia estrutural de detalhe e petrologia permite afirmar que o magmatismo do GCM é sintectônico a uma zona de cisalhamento sinistral, com componente de abertura, relacionada às zonas de cisalhamento Major Gercino e Itajaí, em condicionamento semelhante ao dos granitos Serra dos Macacos e Rio Pequeno (Peternell et al., 2010). Esses mostram assinaturas geoquímicas que sugerem uma fonte comum ao GCM (Martini, 2011), marcando, desse modo, um magmatismo sintectônico aos eventos de cisalhamento transcorrente do CCSb, que representa o estágio pós-colisional do Ciclo Brasiliano no sul do Brasil.

\section{REFERÊNCIAS}

Almeida, F. F. M., Amaral, G., Cordani, U. G., Kawashita, K. (1973). The Precambrian evolution of the South American cratonic margin south of the Amazon River. In: A. E. M. Nairn, F. G. Stehli (Eds.), The Ocean Basin and Margins (v. 1, 411-446). New York: Plenum.

Basei, M. A. S., Siga Jr., O., Masquelin, H., Harara, O. M., Reis Neto, J. M., Preciozi, F. (2000). The Dom Feliciano Belt and the Rio de La Plata Craton: tectonic evolution and correlation with similar provinces of southwestern Africa. In: U. G. Cordani, E. J. Milani, A. Thomaz Filho, D. A. Campos (Eds.), Tectonic Evolution of South America. 
$31^{\text {st }}$ International Geological Congress, 311-334. Rio de Janeiro: PRC.

Basei, M. A. S., Frimmel, H. E., Nutman, A. P., Preciozzi, F. (2008). West Gondwana detrital ages from Neoproterozoic Ribeira and Dom Feliciano belts of South America and comparision with coeval sequences from SW Africa. Journal of the Geological Society of London, 294, 239-256.

Basei, M. A. S., Campos Neto, M. C., Castro, N. A., Nutman, A. P., Wemmer, K., Yamamoto, M. T., Hueck, M., Osako, L., Siga, O., Passarelli, C. R. (2011). Tectonic Evolution of the Brusque Group, Dom Feliciano belt, Santa Catarina, Southernmost Brazil. Journal of South American Earth Science, 32, 324-350.

Basei, M. A. S., Campos Neto, M. C., Lopes, A. C., Nutman, A. P., Liu, D., Sato, K. (2013). Polycyclic evolution of Camboriú Complex migmatites, Santa Catarina, Southern Brazil: integrated $\mathrm{Hf}$ isotopic and $\mathrm{U}-\mathrm{Pb}$ age zircon evidence of episodic reworking of a Mesoarchean juvenile crust. Brasilian Journal of Geology, 43(3), 427-443.

Bitencourt, M. F., Hackspacher, P. C., Nardi, L. V. S. (1989). A Zona de Cisalhamento Major Gercino-Santa Catarina. Simpósio Nacional de Estudos Tectônicos. 214216. Natal: SBG.

Bitencourt, M. F., Nardi, L. V. S. (1993). Late- to Postcollisional Brasiliano Magmatism in Southernmost Brazil. Anais da Academia Brasileira de Ciências, 65(1), 3-16.

Bitencourt, M. F., Nardi, L. V. S. (2000). Tectonic setting and sources of magmatism related to the Southern Brazilian Shear Belt. Revista Brasileira de Geociências, 30(1), 186-189.

Bitencourt, M. F., Nardi, L. V. S. (2004). The role of xenoliths and flow segregation in the genesisand evolution of the Paleoproterozoic Itapema Granite, a crustally derived magma of shoshonitic affinity from southern Brazil. Lithos, 73, 1-19.

Chemale, F., Hartmann, L. A., Silva, L. C. (1995). Stratigraphy and tectonism of the Precambrian and Early Paleozoic units in southern Brazil and Uruguay - Excursion Guidebook. Acta Geologica Leopoldensia, 42, 4-115.

Debat, P., Soula, J. C., Kubin, L., Vidal, J. L. (1978). Optical studies of natural deformation microstructures in feldspars (gneiss and pegmatites from Occitania, Southern France). Lithos, 11, 133-145.

Florisbal, L. M. (2011). Petrogênese de Granitos Sintectônicos em ambiente pós-colisional do Escudo Catarinense: Estudo integrado de Geologia Estrutural, Geoquímica Elemental e Isotópica $\mathrm{Sr}-\mathrm{Nd}-\mathrm{Pb}$ e Geocronologia U-Pb em zircão. Tese (Doutorado). São Paulo: USP.

Florisbal, L. M. F., Bitencourt, M. F., Janasi, V. A., Nardi, L. V. S., Heaman, L. M. (2012a). Petrogenesis of syntectonic granites emplaced at the transition from thrusting to transcurrent tectonics in post-collisional setting: whole-rock and $\mathrm{Sr}-\mathrm{Nd}-\mathrm{Pb}$ isotope geochemistry in the Neoproterozoic Quatro Ilhas and Mariscal granites, southern Brazil. Lithos, 153, 53-71.

Florisbal, L. M. F., Janasi, V. A., Bitencourt, M. F., Heaman, L. M. (2012b). Space-time relation of post-collisional granitic magmatism in Santa Catarina, southern Brazil: U-Pb LA-MC-ICP-MS zircon geochronology of coeval mafic-felsic magmatism related to the Major Gercino Shear Zone. Precambrian Research, 216, 132-151.

Florisbal, L. M. F., Janasi, V. A., Bitencourt, M. F., Nardi, L. V. S., Heaman, L. M. (2012c). Contrasted crustal sources as defined by whole-rock and $\mathrm{Sr}-\mathrm{Nd}-\mathrm{Pb}$ isotope geochemistry of Neoproterozoic early post-collisional granitic magmatism within the Southern Brazilian Shear Belt, Camboriú, Brazil. Journal of South American Earth Science, 39, 24-43.

Hartmann, L. A., Bitencourt, M. F., Santos, J. O., McNaughton, N. J., Rivera, C. B., Betiollo, L. (2003). Prolonged Paleoproterozoic magmatic participation im the Neoproterozoic Dom Feliciano belt, Santa Catarina, Brazil, based on zircon U-Pb SHRIMP geochronology. Journal of South American Earth Science, 16, 477-492.

Hartmann, L. A., Silva, L. C., Orlandi Filho, V. (1979). Complexo Granulítico de Santa Catarina - Descrição e implicações genéticas. Acta Geológica Leopoldensia, 6, 93-112.

Jensen, L. N., Starkey, J. (1985). Plagioclase microfabrics in a ductile shear zone from the Jotun Nappe, Norway. Journal of Structural Geology, 7, 527-541.

Kruhl, J. H. (1996). Prism- and basis-parallel subgrain boundaries in quartz: a microstructural geothermobarometer. Journal of Metamorphic Geology, 14, 581-589.

Lopes, A. P. (2008). Geologia do Complexo Camboriú (SC). Tese (Doutorado). São Paulo: USP.

Mainprice, D., Bouchez, J. L., Blumenfeld, P., Tubia, J. M. (1986). Dominant c slip in naturally deformed quartz: implications for dramatic plastic softening at high temperature. Geology, 14, 819-822. 
Martini, A. (2011). Geologia Estrutural e Petrologia do Granito Corre-mar, região de Balneário Camboriú, SC. Trabalho de Graduação. Porto Alegre: UFRGS.

Olsen, T. S., Kohlstedt, D. L. (1985). Natural deformation and recrystallization of some intermediate plagioclase feldspars. Tectonophysics, 111, 107-131.

Passchier, C. W. (1982). Mylonitic Deformation in the Saint-Barthélemy Massif, French Pyrennes, with emphasis on the genetic relationship between ultramylonite and pseudotachylyte. Paper of Guadalupe Geological Survey, 1(16), 1-173.

Passchier, C. W., Trouw, R. A. J. (2005). Microtectonics. Berlin: Springer, 366 p.

Peternell, M., Bitencourt, M. F, Kruhl, J. H., Stäb, C. (2010). Macro and microstructures as indicators of the development of syntectonic granitoids and host rocks in the Camboriú region, Santa Catarina, Brazil. Journal of South American Earth Sciences, 29, 738-750.

Rivera, C. B., Bitencourt, M. F., Nardi, L. V. S. (2004). Integração de Parâmetros Físicos do Magma e Composição Química dos Minerais na Petrogênese do Granito Itapema. Revista Brasileira de Geociências, 34(3), 361-372.

Shigematsu, M. (1999). Dynamic recrystallization in deformed plagioclase during progressive shear deformation. Tectonophysics, 305, 437-452.

Silva, L. C. (1991). O Cinturão metavulcanossedimentar Brusque e a evolução policíclica das faixas dobradas proterozóicas no sul do Brasil: uma revisão. Revista Brasileira de Geociências, 21, 60-73.
Silva, L. C., Armstrong, R., Pimentel, M. M., Scandolara, J., Ramgrab, G., Wildner, W., Angelim, L. A., Vasconcelos, A. M., Rizzoto, G., Quadros, M. E. S., Sander, A., Rosa, A. L. Z. (2002). Reavaliação da evolução geológica em terrenos pré-cambrianos brasileiros com base em novos dados U-Pb SHRIMP, Parte III: províncias Borborema, Mantiqueira Merdidional e Rio Negro-Juruena. Revista Brasileira de Geociências, 32, 529-544.

Silva, L. C., McNaughton, N. J., Fletcher, I. R. (2005). SHRIMP U/Pb zircon geochronology of Neoproterozoic crustal granitoids (Southern Brazil): a case for discrimination of emplacement and inherited ages. Lithos, 82, 503-525.

Stipp, M., Stünitz, Heilbronner, R., Schmid, S. M. (2002). The eastern Tonale fault zone: a "natural laboratory" for crystal plastic deformation of quartz over a temperature range from 250 to $700^{\circ} \mathrm{C}$. Journal of Structural Geology, 24, 1861-1884.

UFRGS (2000). Mapeamento Geológico 1:25000 de parte das folhas Camboriú (MI2894/2) e Itajaí (2882/4), SC. 7 vol. Trabalho de Graduação do Curso de Geologia. Porto Alegre: UFRGS.

Vidal, J. L., Kubin, L., Debat, P., Sousa, J. L. (1980). Deformation and dynamic recrystallization ok K-feldspar augen in orthogneiss from Montagne Noir, Occitania. Lithos, 13, 247-257.

Weinberg, R., Sial, A. N., Mariano, G. (2004). Close spatial relationship between plutons and shear zones. Geology, 32, 377-380.

Yund, R. A., Tullis, J. (1991). Compositional changes of minerals associated with dynamic recrystallization. Contribuition to Mineral Petrology, 108, 346-355. 